\title{
Physician Supply During the Coronavirus Disease 2019 (COVID-19) Crisis: the Role of Hazard Pay
}

\author{
Gregory W. Ruhnke, MD, MS, MPH®
}

Section of Hospital Medicine, Department of Medicine, University of Chicago, Chicago, IL, USA.

$\mathrm{J}$ Gen Intern Med 35(8):2433-4

DOI: $10.1007 / \mathrm{s} 11606-020-05931-\mathrm{x}$

(c) Society of General Internal Medicine 2020

$\mathrm{T}$ he coronavirus disease 2019 (COVID-19) crisis has pushed the limits of our health care infrastructure, including the labor components of health system capacity, given the increasing incidence of clinically significant nosocomial infection with health care workers becoming exposed, infected, and overworked.

The options for rapidly increasing the physician labor supply include physicians working outside their typical area of practice (e.g., shifting their site of work to the emergency room or inpatient units), retired physicians re-entering the workforce, substitution through alternative advanced practice providers (such as nurse practitioners and physician assistants), and early graduation of medical students. Rapid licensure of retired physicians has received a great deal of media attention.

Many medical schools have encouraged their students to consider early graduation to work within their hospital system as interns. This has the advantage of immediately providing skilled, trained physicians who, based on demographic characteristics, are generally at low risk of deleterious outcomes in the event of either a community-acquired or health careassociated COVID-19 infection. Since the case fatality rate of COVID-19 patients over age 60 ranges from 3.5 to $20.2 \%$, physicians returning to work from retirement may create a substantial number of COVID-19-related deaths (and increase ventilator demand) as a result of in-hospital transmission. Such a migration of older physicians into the hospital setting would be extremely concerning - in one of the original case series, of those infected, $29 \%$ were health care workers. ${ }^{1}$

There are other reasons to consider early graduation of medical students as a viable source of physician supply to meet mutual needs. According to one study of 16,394 internal medicine residents in 2008-2009, average educational debt was greater than $\$ 100,000$ and $\$ 200,000$ among $40.2 \%$ and $13.6 \%$, respectively. ${ }^{2}$ A study of 3083 graduating family

Received April 11, 2020

Accepted May 18, 2020

Published online June 10, 2020 medicine residents found that $58 \%$ reported having > $\$ 150,000$ in educational debt and $26 \%$ reported having $>$ $\$ 250,000 .^{3}$ Debt indeed creates a dramatic financial burden on physicians-in-training and those early in their careers, making highly compensated employment opportunities extremely valuable.

Compensating differentials such as hazard pay have historically been applied to compensate workers for tasks that are either risky or particularly arduous. ${ }^{4}$ Underlying the theory of such differentials are the assumptions that workers must be aware of the hazards present, be averse to those hazards, and have alternative job options. These assumptions are based on the ethical avoidance of coercion and the principle that the choice to seek hazard pay should reflect a utility-maximizing rational decision based on complete and symmetric information. Although the COVID-19 pandemic has raised the issue of hazard pay for those who provide "essential" services that may require an exposure risk, only $26 \%$ of surveyed employers indicated they are planning to provide hazard pay. ${ }^{5}$ Compensating wage differentials for medical students willing to graduate early may maximize their personal utility while ameliorating the physician shortage during the current crisis. From a societal perspective, this would optimize allocation of low-risk physician labor capacity.

Most internal medicine residents are paid between $\$ 50,000$ and $\$ 60,000$ per year. If they voluntarily started residency early and received substantial hazard pay, this would allow them to significantly reduce their educational debt. A large debt burden has been associated with trainee choice of more lucrative specialty fields of medicine, ${ }^{6}$ as well as a propensity to moonlight and reduced likelihood of seeking a career in academic medicine. ${ }^{7}$ As a result, hazard pay offered to medical students willing to risk exposure to COVID-19 now may reduce their debt burden and potentiate the creation of more primary care physicians, a dearth of whom has been a significant health policy concern. Since moonlighting during graduate medical education exacerbates trainees' sleep deprivation while diminishing their educational focus, a medical student graduating early in 2020 to provide a societal good while earning hazard pay may have numerous benefits.

In addition to graduating medical students, younger physicians have significant debt burdens and financial pressures. Many newly constructed COVID-19 units are staffed by physicians who have recently completed training, although anecdotal evidence suggests they are not receiving adequate 
compensation differentials, consistent with the non-physician data cited above. Requests from medical center leadership for low-risk (i.e., younger) physicians, perhaps with subtle pressure, to work in such units without appropriate compensation is ethically suspect, and may in some cases be tantamount to coercion. It is important to acknowledge that many health care institutions are facing budgetary hardships for a variety of reasons due to this pandemic, which may pose considerable barriers to financing compensation differentials. However, there are several ways in which hazard pay might be financed based on local considerations and institutional structures: (a) small compulsory contributions from physicians (perhaps exempting those required to take unpaid furloughs) at a given institution not caring for COVID-19 patients by choice or due to risk factors for bad outcomes if infected; (b) public funding, such as the Coronavirus Preparedness and Response Supplemental Appropriations Act of 2020; and (c) private foundations offering funding for COVID-19 response efforts.

Hazard pay could of course be considered for all physicians risking their health to care for infected patients. Also, a corollary consideration beyond the scope of this piece is supplementary life insurance for all health care workers who succumb to a COVID-19 infection. However, the focus of this viewpoint is to propose an economically efficient method of bringing physicians to the bedside who would otherwise not be caring for COVID-19 patients. Offering an incentive to those willing and/or able to risk infection is ethically preferable to subtly or explicitly coercing junior physicians to take risks against their will without a reward.

Ethical dilemmas around compensating differentials most often center on workers' comprehension of the hazards present, as well as their magnitude. ${ }^{4}$ On the one hand, graduating medical students should be sufficiently intelligent and welltrained to understand that the choice to graduate early for the public good includes both the opportunity costs of their alternative plans and the risks of COVID-19 exposure. The risk of exposure, transmission, and clinically significant infection is difficult even for the Centers for Disease Control and Prevention to quantify, primarily because of imprecise estimates regarding the proportion of cases that result from asymptomatic carriers. However, regardless of the uncertainty of risk estimates among medical students voluntarily graduating early, the risks to older physicians re-entering practice from retirement is clearly substantial. A significant compensation differential for those at low risk of deleterious outcomes voluntarily working at the front lines is far more acceptable from economic and ethical perspectives than the alternatives. These include subtle coercion without compensation, forcing physicians to work outside their usual scope of practice, or utilizing the services of older physicians, whose work-related exposure may markedly increase the burden on an alreadyoverwhelmed health care system. Intelligent and judicious use of hazard pay models has the potential to maximize aggregate societal welfare.

Corresponding Author: Gregory W. Ruhnke, MD, MS, MPH; Section of Hospital Medicine, Department of Medicine, University of Chicago, Chicago, IL, USA (e-mail: gruhnke@medicine.bsd.uchicago. edu).

\section{REFERENCES}

1. Wang D, Hu B, Hu C, et al. Clinical Characteristics of 138 Hospitalized Patients With 2019 Novel Coronavirus-Infected Pneumonia in Wuhan, China. JAMA 2020;323:1061-9.

2. West CP, Shanafelt TD, Kolars JC. Quality of life, burnout, educational debt, and medical knowledge among internal medicine residents. JAMA 2011;306:952-60.

3. Bazemore A, Peterson L, Jetty A, Wingrove P, Petterson S, Phillips R. Over Half of Graduating Family Medicine Residents Report More Than \$150,000 in Educational Debt. J Am Board Fam Med 2016;29:180-1.

4. Robinson JC. Hazard pay in unsafe jobs: theory, evidence, and policy implications. Milbank Q 1986;64:650-77.

5. https://www.worldatwork.org/workspan/articles/how-organizations-arehandling-rewards-and-hazard-pay-decisions-in-a-covid-19-world. Accessed Apr 14, 2020.

6. Grayson MS, Newton DA, Thompson LF. Payback time: the associations of debt and income with medical student career choice. Med Educ 2012;46:983-91.

7. Steiner JW, Pop RB, You J, et al. Anesthesiology residents' medical school debt influence on moonlighting activities, work environment choice, and debt repayment programs: a nationwide survey. Anesth Analg 2012;115:170-5.

Publisher's Note: Springer Nature remains neutral with regard to jurisdictional claims in published maps and institutional affiliations. 